\title{
Crescimento radicular e aéreo de cultivares de arroz de terras altas em função da calagem
}

\author{
Carlos Alexandre Costa Crusciol ( $)$ ); Mauricio Antonio Cuzato Mancuso ( $\left.{ }^{1 *}\right)$; Rodrigo Arroyo Garcia $\left({ }^{2}\right)$; \\ Gustavo Spadotti Amaral Castro (') \\ (') Universidade Estadual Paulista, Faculdade de Ciências Agronômicas, Caixa Postal 237, 18603-970 Botucatu (SP), Brasil. \\ (2) Embrapa Agropecuária Oeste, Caixa Postal 661, 79804-970 Dourados (MS), Brasil. \\ (*) Autor correspondente: macmancuso@fca.unesp.br
}

Recebido: 8/set./2011; Aceito: 8/mar./2012

\section{Resumo}

O presente trabalho teve como objetivo avaliar o crescimento radicular e da parte aérea, além da eficiência de absorção de nutrientes pelas cultivares de arroz Caiapó e Maravilha, em função da calagem. O experimento foi desenvolvido em casa de vegetação, sendo os tratamentos constituídos pelas cultivares Caiapó e Maravilha combinadas com os índices de saturação por bases (V\%) de 10, 40 e 70. O delineamento experimental utilizado foi inteiramente casualizado, com quatro repetições. Foram avaliados o número de perfilhos, comprimento radicular, matéria seca de raízes, folhas e colmos, o teor foliar e a eficiência de absorção dos macronutrientes. De forma geral, observou-se que a cultivar moderna superou a tradicional em matéria seca de raízes, comprimento radicular, número de colmos, matéria seca de colmos e da parte aérea, além de acumular mais nutrientes a cultivar tradicional, mesmo nas condições de maior acidez. No entanto, os teores de nutrientes foram maiores na cultivar Caiapó. A cultivar Maravilha possui maior crescimento radicular e da parte aérea, nos diversos níveis de acidez, enquanto a Caiapó tem maior eficiência de absorção dos nutrientes do solo. A V\% de 40 é a mais efetiva para ambas as cultivares.

Palavras-chave: Oryza sativa, acúmulo de nutrientes, raiz, eficiência de absorção.

\section{Root and shoot growth of upland rice cultivars as affected by lime application}

\begin{abstract}
This work aimed to evaluate root growth, shoot development and nutrient absorption efficiency by rice cultivars Caiapó and Maravilha as affected by lime application. The experiment was carried out in a greenhouse, with treatments set up by Caiapó and Maravilha cultivars in combination with the base saturation (V\%) of 10\%, 40\% and 70\%. The experiment was in a randomized complete block design, with four replications. The number of tillers, root length, root dry matter, leaves and stems, leaf content and macronutrients absorption efficiency were evaluated. Comparing cultivars, Maravilha cultivar presented higher root dry weight, root length, number of stems, dry matter of stems and shoot than Caiapó cultivar, as well as accumulated more nutrients in the shoots. On the other hand, nutrient contents were higher in the cultivar Caiapó compared to Maravilha. Maravilha cultivar shows greater root and shoot growth while Caiapó shows higher nutrient absorption efficiency from the soil. The base saturation of $40 \%$ is the most effective for both cultivars.
\end{abstract}

Key words: Oryza sativa, nutrient accumulation, root, absorption efficiency.

\section{INTRODUÇÃO}

A cultura do arroz (Oryza sativa L.) é produzida em praticamente todo o País, sob diferentes condiçóes ou sistemas de produção, destacando-se os ecossistemas de cultivo de arroz em várzeas e o de terras altas, cultivado sem ou com irrigação por aspersão (Alvarez et al., 2005).

Por um lado, dentre os grupos de cultivares de arroz, destacam-se os grupos tradicionais e os modernos. A cultivar Caiapó, pertencente ao grupo tradicional, de ciclo médio, é recomendada para solos mais intemperizados, de baixa fertilidade, em situaçóes de abertura de áreas e reforma de pastagens degradadas, e, em áreas mais férteis, está sujeita a perdas por acamamento (Soratto et al., 2010). Por outro, a cultivar Maravilha, pertencente ao grupo moderno, é recomendada para regióes com baixo risco de veranico ou com disponibilidade de irrigação suplementar por aspersão. Por ser resistente ao acamamento e responsiva à fertilidade do solo, é recomendada para cultivos com alta tecnologia (Morais et al., 2004), sendo seu desenvolvimento comprometido em solos de baixa fertilidade e com elevada toxidez por alumínio. 
Um dos fatores mais limitantes para o desenvolvimento das culturas graníferas em solos tropicais é a acidez do solo (Fageria e Baligar, 2008). Dessa forma, o uso de calcário é prática comum no Brasil, pois induz benefícios diretos às plantas cultivadas mediante correção da acidez do solo, diminuindo a toxidez por alumínio e manganês, aumentando os teores de cálcio às plantas, fundamental para o crescimento radicular. Além disso, a calagem pode aumentar a disponibilidade de nitrogênio, fósforo, enxofre e molibdênio, reduzir a disponibilidade de ferro, cobre, manganês e zinco, além de aumentar a capacidade de troca catiônica e a mineralização da matéria orgânica do solo (Oliveira et al., 2002; FAgeria e Baligar, 2008).

Para o arroz de terras altas, no Estado de São Paulo, recomenda-se a aplicação de calcário para elevar a saturação por bases a 50\% (CANTARella e Furlani, 1997), pois é uma planta relativamente tolerante à acidez do solo (Soratto et al., 2010). Porém, dentro dessa espécie, há cultivares que diferem quanto à presença do $\mathrm{Al}$ e à calagem. Neste contexto, plantas com sistema radicular capaz de se desenvolver e explorar o perfil do solo, mesmo em condições de elevada acidez, é fundamental para a absorção de água e nutrientes pelas plantas (Roy e MANDAL, 2005).

De acordo com Matsuo e Mochizuki (2009), cultivares de terras altas possuem características de sistema radicular profundo e alta relação raiz/parte aérea, conferindo resistência à seca e maior rusticidade às plantas, porém com baixo potencial produtivo em relação às cultivares dos ecossistemas de várzea. Ademais, foi demonstrada por diversos autores a existência de inúmeras diferenças entre as cultivares de terras altas quanto à capacidade de absorção e utilização de nutrientes (FAGERIA et al., 1995). Essas diferenças estão relacionadas a processos morfológicos e fisiológicos da cultura, permitindo melhor aproveitamento da radiação luminosa, ou mudanças favoráveis no $\mathrm{pH}$ rizosférico, auxiliando na absorção de nutrientes (FAGERIA et al., 1995).

As cultivares do grupo moderno expressam melhor seu rendimento na ausência de deficiência hídrica em solos bem preparados (adubação e calagem), enquanto as do grupo tradicional possuem melhor capacidade para suportar condiçôes adversas de deficiência hídrica e de fertilidade do solo (Heinemann et al., 2011). Esse fato ocorre, pois as plantas necessitam de ajustes para elevar sua tolerância a estresses, sendo eles fisiológicos, como o ajuste na partiçâo de fotoassimilados, e/ou morfológicos, como a variação da relação raiz/parte aérea e a emissão de raízes mais finas, com maior capacidade de absorção de nutrientes (Fornasieri Filho e Fornasieri, 1993). Neste contexto, Lafitte et al. (2001) citados por Henry et al. (2011), trabalhando com os principais grupos de arroz, reportaram a existência de diferenças morfológicas no desenvolvimento radicular das cultivares. Diante do exposto, partiu-se da hipótese de que em materiais tradicionais e modernos há diferenças quanto à morfologia de raiz, podendo ter comportamento distinto com a aplicação de corretivos. Assim, objetivou-se avaliar o crescimento radicular e da parte aérea, além da eficiência de absorção de nutrientes das cultivares de arroz Caiapó (tradicional) e Maravilha (moderno), em função da calagem.

\section{MATERIAL E MÉTODOS}

O experimento foi desenvolvido em casa de vegetação, utilizando-se o solo proveniente da camada arável de um Latossolo Vermelho Distroférrico de textura média (EMBRAPA, 2006), com $590 \mathrm{~g} \mathrm{~kg}^{-1}$ de areia, $340 \mathrm{~g} \mathrm{~kg}^{-1}$ de argila e $70 \mathrm{~g} \mathrm{~kg}^{-1} \mathrm{de}$ silte. O solo foi seco ao ar e passado em peneira com malha de $2 \mathrm{~mm}$, e, em seguida, amostras foram coletadas para análise química (RAIJ et al., 2001), que resultou nos seguintes valores: $\mathrm{pH}\left(\mathrm{CaCl}_{2}\right)=3,8 ; \mathrm{P}_{\text {resina }}=2 \mathrm{mg} \mathrm{dm}^{-3} ; \mathrm{K}=0,2$ $\mathrm{mmol}_{\mathrm{c}} \mathrm{dm}^{-3} ; \mathrm{Ca}=5 \mathrm{mmol}_{\mathrm{c}} \mathrm{dm}^{-3} ; \mathrm{Mg}=1 \mathrm{mmol}_{\mathrm{c}} \mathrm{dm}^{-3}$; $\mathrm{H}+\mathrm{Al}=52 \mathrm{mmol}_{\mathrm{c}} \mathrm{dm}^{-3}, \mathrm{CTC}=58 \mathrm{mmol}_{\mathrm{c}} \mathrm{dm}^{-3} \mathrm{eV} \%=10$. A capacidade de campo da porção de solo desestruturada (peneirada), sob drenagem livre, foi determinada a $-0,03 \mathrm{MPa}$ no aparelho extrator de RicHARDS (EMBRAPA, 1997), e o valor observado foi de $210 \mathrm{~g} \mathrm{~kg}^{-1}$.

Os tratamentos foram constituídos pelas cultivares Caiapó (grupo tradicional) e Maravilha (grupo moderno) combinadas com as doses de 0,1912 e $3824 \mathrm{~kg} \mathrm{ha}^{-1} \mathrm{de} \mathrm{cal-}$ cário dolomítico (PRNT 93\%), visando obter a saturação por bases de 10, 40 e 70, respectivamente. As doses foram calculadas pelo método da saturação por bases, proposto por Raij et al. (1997), em que a necessidade de calcário é calculada pela fórmula: $\mathrm{NC}\left(\mathrm{t} \mathrm{ha}^{-1}\right)=\mathrm{CTC}\left(\mathrm{V}_{2}-\mathrm{V}_{1}\right) / 10$ PRNT, sendo CTC a capacidade de troca de cátions do solo, expressa em mmol $\mathrm{dm}^{-3} ; \mathrm{V}_{2}$, a saturação por bases esperada $\mathrm{e}$ $\mathrm{V}_{1}$, a saturaçáo por bases do solo, ambos expressos em porcentagem, e PRNT, o poder relativo de neutralizaçáo total, também expresso em porcentagem. O delineamento utilizado foi inteiramente casualizado, com quatro repetições.

Aplicou-se calcário dolomítico nas doses referentes aos tratamentos e o solo foi posteriormente mantido em sacos de plástico por 30 dias com o teor de água em torno de $210 \mathrm{~g} \mathrm{~kg}^{-1}$ (capacidade de campo). Após trinta dias de incubaçáo, o solo foi novamente peneirado para a aplicação de $40 \mathrm{mg} \mathrm{dm}^{-3}$ de $\mathrm{P}_{2} \mathrm{O}_{5}$ (superfosfato simples), $50 \mathrm{mg} \mathrm{dm}^{-3}$ de $\mathrm{N}$ (ureia), $100 \mathrm{mg} \mathrm{dm}^{-3}$ de $\mathrm{K}$ (cloreto de potássio), $3 \mathrm{mg} \mathrm{dm}^{-3} \mathrm{de} \mathrm{B} \mathrm{e} 5 \mathrm{mg} \mathrm{dm}^{-3} \mathrm{de} \mathrm{Zn}$. O solo fertilizado foi acomodado em vasos de $12 \mathrm{dm}^{3}$ de forma a ser estabelecida uma densidade próxima a $1,2 \mathrm{~g} \mathrm{~cm}^{-3}$, correspondente às condiçôes de campo. No início do estágio de perfilhamento, 20 dias após a emergência das plantas de arroz, foram aplicados mais $50 \mathrm{mg} \mathrm{dm}^{-3}$ de $\mathrm{N}$ (ureia).

Foram cultivadas três plantas por vaso, e aos 58 dias após a emergência, quando estavam no estágio de diferenciação floral, foi realizada a contagem do número de perfilhos em cada unidade experimental. Diariamente, os vasos foram pesados e, quando necessário, aplicou-se água 
para que os teores de água dos vasos fossem mantidos próximos da capacidade de campo. A seguir, as plantas foram seccionadas no colo, rente à superfície do solo, separando a parte aérea do sistema radicular.

As raízes foram separadas do solo por lavagem em água corrente sobre peneira com malha de $0,5 \mathrm{~mm}$. Após a lavagem de todo o sistema radicular de cada unidade experimental, as raízes foram mantidas em solução de etanol 30\%. Imagens das raízes foram digitalizadas em um "scanner" de leitura ótica, na resoluçáo de 250 dpi, e analisadas pelo programa "Win Mac Rhizo", versão 3.8-b (Regent Instrument Inc., Quebec-Canadá), para obtençáo do comprimento radicular (Pavinato et al., 2009).

Em seguida, as raízes foram secas em estufa a $65^{\circ} \mathrm{C}$ por 48 horas, até que atingiram massa constante. Posteriormente, foi determinada a matéria seca radicular. Após o corte da parte aérea das plantas e a separaçáo do sistema radicular, as amostras foram desidratadas em estufa de aeração forçada a $65^{\circ} \mathrm{C}$ por 72 horas, até a obtenção de massa constante. Após desidratadas, alíquotas da matéria seca da parte aérea das plantas de arroz foram separadas para a determinação dos teores de $\mathrm{N}, \mathrm{P}, \mathrm{K}, \mathrm{Ca}, \mathrm{Mg}$ e S, conforme procedimentos propostos por Malavolta et al. (1997). Desse modo, também foi possível determinar a eficiência de absorção (EA) dos nutrientes, pela fórmula: $\mathrm{EA}\left(\mathrm{mg} \mathrm{g}^{-1}\right)=(\mathrm{mg}$ do nutriente na planta/gramas de matéria seca da raiz de uma planta) (SWIAdER et al., 1994; CASTro et al., 2008), sendo uma ferramenta que contribui para explicar a capacidade que certas cultivares têm de se adaptar às diversas condiçôes de estresses ambientais (SWIADER et al., 1994).

Todos os dados obtidos foram submetidos à análise de variância e as médias comparadas pelo teste t a $5 \%$ de probabilidade.

\section{RESULTADOS E DISCUSSÃO}

A matéria seca de raiz foi influenciada por todas as fontes de variação (Tabela 1). Mesmo no caso do menor índice de saturação por bases, a cultivar Maravilha proporcionou maior produção de matéria seca, com valor médio de $93 \%$ superior à cultivar Caiapó. Com relação à elevaçáo das doses de calcário, ambos os genótipos foram responsivos, com valores máximos obtidos em doses intermediárias de calcário. No entanto, essa variável não é a mais indicada para avaliar o potencial de exploração do solo pelas raízes, visto que o maior volume de solo alcançado pelas raízes é dependente do comprimento radicular. Enfatizando o sistema radicular, o ideal é aquele que tenha maior comprimento, ou seja, maior volume de solo explorado, caracterizando raízes compridas e vigorosas, o que seria de extrema importância para a planta, culminando em benefícios quanto à qualidade física do solo e incrementos de matéria orgânica no perfil do solo (GARCIA e Rosolem, 2010). O comprimento radicular foi maior para a cultivar Maravilha e, quanto à aplicação de calcário, o índice de saturação por bases de 40 propiciou valores mais expressivos, independentemente do genótipo (Tabela 1), evidenciando valores próximos aos recomendados por Cantarella e Furlani (1997), com V\% de 50. Carvalho-Pupatto et al. (2003), trabalhando com aplicação de corretivos, constataram aumento do crescimento radicular de arroz de terras altas e alegaram que o fato devia-se à melhoria das condiçóes químicas do solo proporcionada pelos produtos. Soratto et al. (2010) verificaram que o comprimento radicular e a matéria seca de raiz das cultivares Caiapó (grupo tradicional) e IAC 202 (grupo moderno) não foram afetadas pela aplicaçấo de calcário, mesmo com os atributos químicos do solo melhorados através da calagem. Este fato pode ser atribuído ao teor inicial de $\mathrm{Ca}, \mathrm{Mg}$ e $\mathrm{K}$ no solo, que culminou na V\% de 37 no tratamento sem aplicação de corretivos. Por outro lado, neste experimento, a cultivar Maravilha foi mais interessante quanto às características de suas raízes, em função da maior produção de matéria seca das raízes e maior volume de solo explorado; a calagem para elevação do V\% para 40 foi suficiente para a obtenção desses resultados. Mesmo nas condiçôes mais restritivas, com maior acidez do solo, observou-se na cultivar do grupo moderno maior comprimento de raízes que o genótipo do grupo tradicional (Tabela 1).

Todas as variáveis da parte aérea das plantas de arroz foram afetadas em função da aplicação dos tratamentos (Tabela 1). Para as cultivares, o genótipo Maravilha foi superior ao Caiapó para número de colmos, matéria seca de colmos e matéria seca da parte aérea. Em relação à calagem, de forma geral, as doses intermediárias de calcário foram iguais ou superiores à dose para elevação da saturaçấo por bases para 70. De fato, as cultivares do grupo moderno, como é o caso da Maravilha, são mais responsivas à calagem e adubação que as do grupo tradicional, o que também foi constatado por Pavinato et al. (2009), em análises da parte aérea das plantas. No entanto, doses intermediárias de calcário foram suficientes para ambas as cultivares estudadas (Tabela 1). Porém, fato relevante que deve ser destacado, é que, de forma geral, no menor índice de saturação por bases, a cultivar moderna também foi superior à tradicional. Soratto e Crusciol (2008) trabalharam com uma cultivar do grupo tradicional e outra moderna, e constataram que a produçâo de matéria seca da parte aérea foi influenciada pela cultivar e pela interação cultivar x calagem. Esses autores também evidenciaram maiores ganhos dessa variável para a cultivar do grupo moderno. A seleção e o cultivo de variedades de arroz mais capacitadas em se desenvolver em áreas com atributos químicos do solo mais restritivos são de fundamental importância nas áreas de sequeiro e sob sistema de semeadura direta, em que a aplicação superficial dos corretivos demora mais para atingir as condiçóes de acidez desejadas (SoratTo et al., 2010). A relação raiz/parte aérea não variou entre as cultivares nem quanto às doses de calcário. Esse fato leva a crer que a cultura tende a manter um equilíbrio, e a ocorrência de prejuízos em um dos fatores será acompanhada de redução do outro fator. 
Tabela 1. Probabilidade do teste $\mathrm{F}$ e valores médios de matéria seca de raiz (MSR), comprimento radicular (CR), número de colmos $\left(\mathrm{N}^{\circ} \mathrm{CO}\right)$, matéria seca de folhas (MSF), matéria seca de colmos (MSCO), matéria seca da parte aérea (MSPA), matéria seca total (MST) e relação raiz/parte aérea (R/PA), em função da cultivar de arroz e de doses de calcário ( $\mathrm{t}$ ha $\left.{ }^{-1}\right)$

\begin{tabular}{|c|c|c|c|c|c|c|c|c|}
\hline \multicolumn{9}{|c|}{ Probabilidade do teste $F$} \\
\hline Fontes de variação & MSR & CR & $\mathrm{N}^{\circ} \mathrm{CO}$ & MSF & MSCO & MSPA & MST & R/PA \\
\hline Cultivares (C) & $<0,001$ & 0,025 & $<0,001$ & 0,079 & $<0,001$ & 0,011 & $<0,001$ & 0,490 \\
\hline $\mathrm{V}(\%)$ & $<0,001$ & $<0,001$ & 0,012 & 0,001 & 0,335 & 0,001 & $<0,001$ & 0,201 \\
\hline $\mathrm{C} \times \mathrm{V}(\%)$ & 0,043 & 0,264 & 0,953 & 0,092 & 0,145 & 0,057 & 0,024 & 0,420 \\
\hline $\mathrm{CV}(\%)$ & 13,03 & 12,76 & 18,56 & 23,18 & 16,92 & 19,75 & 13,44 & 21,00 \\
\hline \multirow{2}{*}{ Cultivares } & & \multicolumn{6}{|c|}{ Doses de calcário (t ha-1) } & \multirow{2}{*}{ Média } \\
\hline & & c & & & & & & \\
\hline \multicolumn{9}{|c|}{ Matéria seca de raiz (g vaso-1) } \\
\hline Caiapó & & \multicolumn{2}{|c|}{$2,59 b B^{(1)}$} & \multicolumn{2}{|c|}{$5,84 \mathrm{aA}$} & \multicolumn{2}{|c|}{$5,39 a A$} & 4,61 \\
\hline Maravilha & & \multicolumn{2}{|c|}{$5,01 \mathrm{aB}$} & \multicolumn{2}{|c|}{$6,74 \mathrm{aA}$} & \multicolumn{2}{|c|}{$6,40 \mathrm{aA}$} & 5,96 \\
\hline Média & & \multicolumn{2}{|c|}{3,80} & \multicolumn{2}{|c|}{6,15} & \multicolumn{2}{|c|}{5,89} & --------- \\
\hline \multicolumn{9}{|c|}{ Comprimento radicular (m vaso-1) } \\
\hline Caiapó & & \multicolumn{2}{|c|}{17,88} & \multicolumn{2}{|c|}{24,45} & \multicolumn{2}{|c|}{19,05} & $20,46 b$ \\
\hline Maravilha & & \multicolumn{2}{|c|}{20,94} & \multicolumn{2}{|c|}{29,43} & \multicolumn{2}{|c|}{19,32} & $23,25 a$ \\
\hline Média & & \multicolumn{2}{|c|}{$19,44 B$} & \multicolumn{2}{|c|}{$26,94 \mathrm{~A}$} & \multicolumn{2}{|c|}{$19,20 B$} & --------- \\
\hline \multicolumn{9}{|l|}{ Número de Colmos } \\
\hline Caiapó & & & & & & & & $3,7 b$ \\
\hline Maravilha & & & & & & & & $6,3 a$ \\
\hline Média & & & & & & & & --------- \\
\hline Matéria seca de folhas & vaso $\left.^{-1}\right)$ & & & & & & & \\
\hline Caiapó & & & & & & & & 3,24 \\
\hline Maravilha & & & & & & & & 3,86 \\
\hline Média & & & & & & & & --------- \\
\hline Matéria seca de colmc & vaso $^{-1}$ ) & & & & & & & \\
\hline Caiapó & & & & & & & & $0,56 b$ \\
\hline Maravilha & & & & & & & & $0,92 a$ \\
\hline Média & & & & & & & & --------- \\
\hline Matéria seca da parte & ea (g vas & & & & & & & \\
\hline Caiapó & & & & & & & & $3,80 \mathrm{~b}$ \\
\hline Maravilha & & & & & & & & $4,78 \mathrm{a}$ \\
\hline Média & & & & & & & & --------- \\
\hline Matéria seca total ( $\mathrm{g}$ V & & & & & & & & \\
\hline Caiapó & & & & & & & & 8,41 \\
\hline Maravilha & & & & & & & $A B$ & 10,74 \\
\hline Média & & & & & & & & --------- \\
\hline Raiz/Parte Aérea & & & & & & & & \\
\hline Caiapó & & & & & & & & 1,22 \\
\hline Maravilha & & & & & & & & 1,29 \\
\hline Média & & & & & & & & -------- \\
\hline
\end{tabular}

Médias seguidas da mesma letra minúscula na coluna e maiúscula na linha nấo diferem entre si pelo teste t $(\mathrm{p}>0,05)$.

Com exceção dos teores de nitrogênio, os demais elementos avaliados (P, K, Ca, Mg e S) no tecido vegetal das plantas de arroz foram influenciados pela calagem, cultivar ou interação desses dois fatores (Tabela 2). O comportamento do $\mathrm{P}$ contrasta os resultados obtidos por MAUAD et al. (2004), onde a cultivar do grupo moderno IAC 202 proporcionou maior teor foliar de P. Segundo os autores, esse resultado se deve à maior capacidade dos materiais desse grupo em absorverem o $\mathrm{P}$ em solos previamente corrigidos. Contudo, os menores teores obtidos na diagnose foliar da cultivar Maravilha não influenciaram o acúmulo de P (Tabela 3), evidenciando que a cultivar moderna foi mais apta na produção de fitomassa (Tabela 1), gerando o "efeito diluiçáo" nos teores dos nutrientes na parte aérea das plantas. Os teores de P do genótipo Caiapó foram superiores, em todas as condiçóes de calagem (Tabela 2). Segundo Guimaráes et al. (2007), a identificação de germoplasma capaz de utilizar os nutrientes menos disponíveis no solo se constitui em importante estratégia de baixo custo para promover a sustentabilidade da agricultura das regiôes marginalizadas.

Como era esperado, os teores de $\mathrm{Ca}$ e $\mathrm{Mg}$ foram aumentados em função das doses crescentes de calcário. No entanto, observou-se esse comportamento nos dois 
Tabela 2. Probabilidade do teste $\mathrm{F}$ e valores médios para os teores de nitrogênio $(\mathrm{N})$, fósforo $(\mathrm{P})$, potássio $(\mathrm{K})$, cálcio $(\mathrm{Ca})$, magnésio $(\mathrm{Mg})$ e enxofre $(\mathrm{S})$, nas plantas de arroz, em função da arroz e de doses de calcário ( $\mathrm{t}$ ha ${ }^{-1}$ )

\begin{tabular}{|c|c|c|c|c|c|c|}
\hline \multicolumn{7}{|c|}{ Probabilidade do teste $\mathrm{F}$} \\
\hline Fontes de variação & $\mathbf{N}$ & $\mathbf{P}$ & K & Ca & $\mathrm{Mg}$ & $\mathbf{S}$ \\
\hline Cultivares (C) & 0,382 & 0,023 & 0,009 & 0,373 & $<0,001$ & 0,508 \\
\hline $\mathrm{V}(\%)$ & 0,266 & 0,422 & 0,213 & $<0,001$ & $<0,001$ & 0,013 \\
\hline $\mathrm{C} \times \mathrm{V}(\%)$ & 0,710 & 0,955 & $<0,001$ & 0,003 & $<0,001$ & 0,279 \\
\hline CV (\%) & 8,78 & 24,88 & 9,33 & 7,50 & 9,39 & 14,67 \\
\hline \multirow{2}{*}{ Cultivares } & \multicolumn{5}{|c|}{ Doses de calcário (t ha-1) } & \multirow{2}{*}{ Média } \\
\hline & & 0 & & & 3,8 & \\
\hline \multicolumn{7}{|l|}{$\mathrm{N}\left(\mathrm{g} \mathrm{kg}^{-1}\right)$} \\
\hline Caiapó & & 39,3 & & & 39,7 & 38,5 \\
\hline Maravilha & & 38,9 & & & 41,5 & 39,8 \\
\hline Média & & 39,1 & & & 40,6 & -------- \\
\hline \multicolumn{7}{|l|}{$P\left(\mathrm{~g} \mathrm{~kg}^{-1}\right)$} \\
\hline Caiapó & & 2,4 & & & 2,1 & $2,2 a^{(1)}$ \\
\hline Maravilha & & 1,9 & & & 1,7 & $1,7 b$ \\
\hline Média & & 2,2 & & & 1,9 & --------- \\
\hline \multicolumn{7}{|l|}{$\mathrm{K}\left(\mathrm{g} \mathrm{kg}^{-1}\right)$} \\
\hline Caiapó & & $21,0 \mathrm{bB}$ & & & $29,6 a A$ & 26,7 \\
\hline Maravilha & & $33,2 \mathrm{aA}$ & & & $29,5 \mathrm{aAB}$ & 29,9 \\
\hline Média & & 27,1 & & & 29,6 & --------- \\
\hline \multicolumn{7}{|l|}{$\mathrm{Ca}\left(\mathrm{g} \mathrm{kg}^{-1}\right)$} \\
\hline Caiapó & & $7,0 \mathrm{aB}$ & & & $8,7 a A$ & 8,4 \\
\hline Maravilha & & $7,3 a B$ & & & $9,4 a A$ & 8,2 \\
\hline Média & & 7,2 & & & 9,0 & --------- \\
\hline \multicolumn{7}{|l|}{$\mathrm{Mg}\left(\mathrm{g} \mathrm{kg}^{-1}\right)$} \\
\hline Caiapó & & $1,6 \mathrm{aC}$ & & & $3,1 \mathrm{aA}$ & 2,4 \\
\hline Maravilha & & $1,6 a B$ & & & $2,1 \mathrm{bA}$ & 1,9 \\
\hline Média & & 1,6 & & & 2,6 & --------- \\
\hline \multicolumn{7}{|l|}{$\mathrm{S}\left(\mathrm{g} \mathrm{kg}^{-1}\right)$} \\
\hline Caiapó & & 3,5 & & & 2,6 & 2,9 \\
\hline Maravilha & & 3,1 & & & 2,9 & 2,8 \\
\hline Média & & $3,3 \mathrm{~A}$ & & & $2,8 \mathrm{~B}$ & --------- \\
\hline
\end{tabular}

Médias seguidas da mesma letra minúscula na coluna e maiúscula na linha năo diferem entre si pelo teste $\mathrm{t}(\mathrm{p}>0,05)$.

grupos de cultivares. Nesse contexto, a cultivar Caiapó foi responsiva às melhorias das condiçóes químicas do solo, evidenciando também ser material com capacidade produtiva aumentada pelas melhorias do sistema produtivo.

A quantidade de nutrientes acumulada na parte aérea das plantas de arroz está apresentada na tabela 3. Apesar de os teores de $\mathrm{N}$ náo serem afetados pela calagem, o acúmulo desse nutriente foi elevado em função do incremento na produção de matéria seca (Tabela 1), refletindo na quantidade total de $\mathrm{N}$ extraído do solo (Tabela 3). A cultivar Maravilha foi mais apta em acumular $\mathrm{N}$ na parte aérea das plantas, independentemente da dose de calcário, o que é de fundamental importância para a reciclagem de nutrientes (Rosolem et al., 2010) e qualidade de grãos produzidos.

Para o acúmulo de K, novamente o genótipo Maravilha foi o mais eficiente quanto à capacidade em extrair o nutriente do solo. Essas diferenças foram mais consistentes nas condiçôes de maior acidez do solo. Para ambos os genótipos, as maiores médias para o acúmulo de $\mathrm{K}$ ocorreram na saturação por bases de 40. O acúmulo de Ca e Mg evidenciaram o mesmo comportamento quanto aos tratamentos, ou seja, similaridade entre as cultivares e efeito positivo decorrente da aplicaçấo de calcário (Tabela 3). No entanto, as doses intermediárias de calcário foram as mais benéficas para maiores quantidades acumuladas de $\mathrm{Ca}$ e $\mathrm{Mg}$ na parte aérea das plantas de arroz. Fageria (2000), em um experimento com três cultivares de arroz de terras altas, avaliados em função dos diferentes níveis de $\mathrm{pH}$ do solo, constatou resultados semelhantes aos do presente trabalho, no que diz respeito ao acúmulo de $\mathrm{K}$ e $\mathrm{Mg}$, relatando que os maiores valores foram observados em $\mathrm{pH}$ médio (em torno de 5,5). Levando em consideração que o $\mathrm{pH}$ dos solos está relacionado com o índice de saturação por bases, o pH observado por FAGERIA (2000) é equivalente ao V\% entre 40 e 70 do presente trabalho. Para Soratto et al. (2010), o uso de cultivares mais tolerantes à acidez do solo proporciona a obtenção de maiores produtividades das culturas no início do sistema de semeadura direta, quando ainda não houve efetiva correção do solo pela aplicação superficial de corretivos.

A eficiência de absorção dos nutrientes, calculada pela relação entre o teor do nutriente e a massa da matéria seca de raízes produzida, foi afetada pela escolha do genótipo e 
Tabela 3. Probabilidade do teste $\mathrm{F}$ e valores médios para o acúmulo de nitrogênio $(\mathrm{N})$, fósforo $(\mathrm{P})$, potássio $(\mathrm{K})$, cálcio $(\mathrm{Ca})$, magnésio $(\mathrm{Mg})$ e enxofre $(S)$, na parte aérea das plantas, em função da arroz e de doses de calcário $\left(t \mathrm{th}^{-1}\right)$

\begin{tabular}{|c|c|c|c|c|c|c|}
\hline \multicolumn{7}{|c|}{ Probabilidade do teste $\mathrm{F}$} \\
\hline Fontes de variação & $\mathbf{N}$ & $\mathbf{P}$ & K & $\mathrm{Ca}$ & $\mathrm{Mg}$ & $\mathrm{s}$ \\
\hline Cultivares (C) & 0,013 & 0,887 & $<0,001$ & 0,082 & 0,241 & 0,059 \\
\hline $\mathrm{V}(\%)$ & 0,009 & 0,175 & $<0,001$ & $<0,001$ & $<0,001$ & 0,184 \\
\hline $\mathrm{C} \times \mathrm{V}(\%)$ & 0,246 & 0,275 & $<0,001$ & 0,073 & 0,009 & 0,326 \\
\hline $\mathrm{CV}(\%)$ & 23,98 & 34,40 & 15,51 & 21,47 & 24,60 & 26,82 \\
\hline \multirow{2}{*}{ Cultivares } & \multicolumn{5}{|c|}{ Doses de calcário (t ha-1) } & \\
\hline & & & & & 3,8 & Media \\
\hline \multicolumn{7}{|c|}{$\mathrm{N}$ acumulado (mg planta-1 ${ }^{-1}$} \\
\hline Caiapó & \multicolumn{2}{|c|}{87,7} & \multicolumn{2}{|c|}{177,2} & 172,2 & $145,7 b$ \\
\hline Maravilha & \multicolumn{2}{|c|}{170,0} & \multicolumn{2}{|c|}{218,7} & 184,5 & $191,1 \mathrm{a}$ \\
\hline Média & \multicolumn{2}{|c|}{$128,9 \mathrm{~B}^{(1)}$} & \multicolumn{2}{|c|}{$198,0 A$} & $178,4 \mathrm{~A}$ & --------- \\
\hline \multicolumn{7}{|c|}{ P acumulado (mg planta-1) } \\
\hline Caiapó & \multicolumn{2}{|c|}{5,5} & \multicolumn{2}{|c|}{10,0} & 9,5 & 8,3 \\
\hline Maravilha & \multicolumn{2}{|c|}{8,0} & \multicolumn{2}{|c|}{9,0} & 7,5 & 8,2 \\
\hline Média & \multicolumn{2}{|c|}{6,7} & \multicolumn{2}{|c|}{9,5} & 8,5 & -------- \\
\hline \multicolumn{7}{|c|}{ K acumulado (mg planta-1) } \\
\hline Caiapó & \multicolumn{2}{|c|}{$47,0 b B$} & \multicolumn{2}{|c|}{$141,0 a A$} & $127,7 \mathrm{aA}$ & 105,2 \\
\hline Maravilha & \multicolumn{2}{|c|}{$145,0 \mathrm{aA}$} & \multicolumn{2}{|c|}{$150,0 a A$} & $126,5 \mathrm{aA}$ & 140,7 \\
\hline Média & \multicolumn{2}{|c|}{96,0} & \multicolumn{2}{|c|}{145,7} & 127,1 & --------- \\
\hline \multicolumn{7}{|c|}{ Ca acumulado (mg planta ${ }^{-1}$ ) } \\
\hline Caiapó & \multicolumn{2}{|c|}{15,7} & \multicolumn{2}{|c|}{46,5} & 37,5 & 33,2 \\
\hline Maravilha & \multicolumn{2}{|c|}{32,2} & \multicolumn{2}{|c|}{44,5} & 40,5 & 39,1 \\
\hline Média & \multicolumn{2}{|c|}{$24,0 B$} & & & $39,0 \mathrm{~A}$ & -------- \\
\hline Mg acumulado (mg pla & & & & & & \\
\hline Caiapó & & & & & $13,7 \mathrm{aA}$ & 10,2 \\
\hline Maravilha & & & & & $9,2 \mathrm{bAB}$ & 9,0 \\
\hline Média & & & & & 11,5 & --------- \\
\hline $\mathrm{S}$ acumulado (mg plan & & & & & & \\
\hline Caiapó & & & & & 11,2 & 10,7 \\
\hline Maravilha & & & & & 13,0 & 13,4 \\
\hline Média & & & & & 12,1 & -------- \\
\hline
\end{tabular}

Médias seguidas da mesma letra minúscula na coluna e maiúscula na linha năo diferem entre si pelo teste t $(\mathrm{p}>0,05)$.

pelo índice de saturação por bases, além da interação desses fatores (Tabela 4). Quanto à influência do genótipo, para todos os nutrientes avaliados, a cultivar Caiapó foi superior à Maravilha, evidenciando maior eficiência de absorção pelo sistema radicular das plantas pertencentes ao grupo tradicional. Esses resultados evidenciam que mesmo com menor acúmulo de nutrientes e menor produção de massa de raízes (Tabelas 3 e 1 respectivamente), levando em consideração apenas a eficiência de absorção de nutrientes, o genótipo Caiapó foi mais apto em absorver nutrientes com menor comprometimento de fotoassimilados na formação das raízes. Em contrapartida, Gourley et al. (1993) definem como germoplasma eficiente, aquele que requer menos nutriente que o ineficiente para atingir patamares semelhantes de produtividade. Nesse contexto, a cultivar Caiapó foi mais eficiente levando-se em consideração a menor necessidade de uma unidade do teor do nutriente para a produçáo de unidade de massa de raiz (Tabela 4). Por outro lado, em se tratando de quantidade total de raízes e quantidade de nutrientes explorados no solo, a cultivar Maravilha foi mais capacitada, mesmo em condiçóes de solo mais ácido (Tabelas 1 e 3).
Nas condiçóes de maior ou menor acidez do solo, as plantas pertencentes ao grupo tradicional proporcionaram, relativamente, menor gasto de nutrientes para formação das raízes, com exceção do magnésio (Tabela 4), apesar de serem menos capacitadas para produção de matéria seca e acúmulo de nutrientes na parte aérea das plantas.

Desse modo, alteraçôes na morfologia das raízes das plantas pode ser um parâmetro mais interessante na determinaçáo da eficiência de determinado genótipo na exploração do perfil do solo, o que acaba sendo mais trabalhoso quanto às metodologias de determinação. Para LYNCH e BROWN (2001), podem ocorrer alteraçôes na arquitetura radicular das plantas em resposta à deficiência de fósforo. Tem-se observado aumento no crescimento radicular lateral e nas ramificaçôes secundárias laterais, em detrimento do alongamento da raiz primária do feijoeiro. Uma adaptação comumente constatada na maioria das espécies é o aumento do comprimento e da densidade dos pelos absorventes que contribuem para o aumento da absorção de fósforo através da expansão da superfície radicular (LyNch e Brown, 2001). Wissuwwa (2005) observou que a correlação entre a 
Tabela 4. Probabilidade do teste $\mathrm{F}$ e valores médios para eficiência de absorção (mg nutriente g raiz $\left.{ }^{-1}\right)$ de nitrogênio $(\mathrm{N})$, fósforo (P), potássio $(\mathrm{K})$, cálcio $(\mathrm{Ca})$, magnésio $(\mathrm{Mg})$ e enxofre $(\mathrm{S})$, em função da arroz e de doses de calcário $\left(\mathrm{t} \mathrm{ha}^{-1}\right)$

\begin{tabular}{|c|c|c|c|c|c|c|}
\hline \multicolumn{7}{|c|}{ Probabilidade do teste F } \\
\hline Fontes de variação & $\mathbf{N}$ & $\mathbf{P}$ & K & $\mathrm{Ca}$ & Mg & S \\
\hline Cultivares (C) & 0,002 & $<0,001$ & 0,042 & $<0,001$ & $<0,001$ & $<0,001$ \\
\hline $\mathrm{V}(\%)$ & $<0,001$ & $<0,001$ & $<0,001$ & 0,001 & 0,063 & $<0,001$ \\
\hline $\mathrm{C} \times \mathrm{V}(\%)$ & 0,002 & 0,022 & 0,377 & 0,004 & 0,215 & $<0,001$ \\
\hline CV(\%) & 24,56 & 27,15 & 18,01 & 18,15 & 19,35 & 14,45 \\
\hline \multirow{2}{*}{ Cultivares } & \multicolumn{5}{|c|}{ Doses de calcário (t ha $\left.{ }^{-1}\right)$} & \multirow{2}{*}{ Média } \\
\hline & & & 1,9 & & 3,8 & \\
\hline \multicolumn{7}{|l|}{$\mathrm{N}\left(\mathrm{mg} \mathrm{g}^{-1}\right)$} \\
\hline Caiapó & & & $18,98 \mathrm{aB}$ & & $22,27 \mathrm{aB}$ & 29,67 \\
\hline Maravilha & & & $18,22 \mathrm{aA}$ & & $19,46 a A$ & 20,44 \\
\hline Média & 35 & & 18,60 & & 20,87 & --------- \\
\hline \multicolumn{7}{|l|}{$P\left(\mathrm{mg} \mathrm{g}^{-1}\right)$} \\
\hline Caiapó & & & $1,10 \mathrm{aB}$ & & $1,20 \mathrm{aB}$ & 1,56 \\
\hline Maravilha & & & $0,76 a A$ & & $0,80 a A$ & 0,90 \\
\hline Média & & & 0,93 & & 1,00 & --------- \\
\hline \multicolumn{7}{|l|}{$\mathrm{K}\left(\mathrm{mg} \mathrm{g}^{-1}\right)$} \\
\hline Caiapó & 25 & & 15,48 & & 15,28 & $18,66 a$ \\
\hline Maravilha & 20 & & 12,57 & & 14,79 & $15,88 b$ \\
\hline Média & & & $14,03 B$ & & $15,03 B$ & -------- \\
\hline \multicolumn{7}{|l|}{$\mathrm{Ca}\left(\mathrm{mg} \mathrm{g}^{-1}\right)$} \\
\hline Caiapó & & & $4,99 a B$ & & $4,90 \mathrm{aB}$ & 6,11 \\
\hline Maravilha & & & $3,74 a A$ & & $4,43 a A$ & 4,20 \\
\hline Média & & & 4,36 & & 4,66 & --------- \\
\hline \multicolumn{7}{|l|}{$\mathrm{Mg}\left(\mathrm{mg} \mathrm{g}^{-1}\right)$} \\
\hline Caiapó & & & 1,37 & & 1,78 & $1,68 a$ \\
\hline Maravilha & & & 0,89 & & 1,01 & $0,95 b$ \\
\hline Média & & & 1,13 & & 1,39 & --------- \\
\hline \multicolumn{7}{|l|}{$\mathrm{S}\left(\mathrm{mg} \mathrm{g}^{-1}\right)$} \\
\hline Caiapó & & & $1,41 \mathrm{aB}$ & & $1,47 a B$ & 2,31 \\
\hline Maravilha & & & $1,17 a B$ & & $1,37 \mathrm{aB}$ & 1,46 \\
\hline Média & & & 1,29 & & 1,42 & --------- \\
\hline
\end{tabular}

Médias seguidas da mesma letra minúscula na coluna e maiúscula na linha năo diferem entre si pelo teste $\mathrm{t}(\mathrm{p}>0,05)$.

absorção de fósforo e o crescimento relativo das raízes sob condições de deficiência de $\mathrm{P}$ era maior que em ambiente de boa disponibilidade de fósforo. Porém, Otani e Ae (1996) observaram que a absorçáo de $\mathrm{P}$ foi fortemente correlacionada com o comprimento radicular em solos com alta disponibilidade de P. Contudo, sabe-se que vários são os fatores que se inter-relacionam e atuam conjuntamente no aumento da eficiência da absorção de $\mathrm{P}$, pois a quantidade adicional de P absorvida em função da maior eficiência externa das raízes, associada à morfologia e à fisiologia, contribuirá para o maior crescimento radicular e este, por sua vez, para o aumento da absorção do nutriente (WISSUWA, 2005).

\section{CONCLUSÃO}

As cultivares Maravilha e Caiapó diferem quanto ao comprimento radicular, porém têm comportamento semelhante com a aplicação de calcário.
A cultivar Maravilha é mais capacitada quanto ao crescimento radicular e à produçáo de fitomassa da parte aérea das plantas, refletindo em maior acúmulo de nutrientes. Esse comportamento é obtido mesmo nas condições de solo mais ácido.

A cultivar Caiapó, pertencente ao grupo tradicional, é mais eficiente na absorção dos nutrientes do solo, comprometendo menos fotoassimilados para a formação das raízes. Em contrapartida, esse processo não resulta em ganhos do sistema radicular e da parte aérea das plantas, em todas as condiçóes de acidez do solo.

A calagem visando elevar a saturação por bases a $40 \%$ é a mais adequada para o crescimento de ambas as cultivares de arroz de terras altas.

\section{REFERÊNCIAS}

ALVAREZ, R.C.F.; CRUSCIOL, C.A.C.; RODRIGUES, J.D.; ALVAREZ, A.C.C. Marcha de absorção de nitrogênio de cultivares 
de arroz de terras altas com diferentes tipos de plantas. Científica, v.34, p.162-169, 2005.

CANTARELLA, H.; FURLANI, P.R. Arroz de sequeiro. In: RAIJ, B.van.; CANTARELLA, H.; QUAGGIO, J.A.; FURLANI, A.M.C (Ed.). Recomendaçóes de adubação e calagem para o Estado de São Paulo. Campinas: IAC, 1997. p.48-49. (Boletim Técnico 100)

CARVALHO-PUPATTO, J.G.; BÜLL, L.T.; CRUSCIOL, C.A.C.; MAUAD, M.; SILVA, R.H. Efeito de escória de alto forno no crescimento radicular e na produtividade de arroz. Pesquisa Agropecuária Brasileira, v.38, p.1323-1328, 2003.

CASTRO, G.S.A.; BOGIANI, J.C.; SILVA, M.G.; GAZOLA, E.; ROSOLEM, C.A. Tratamento de sementes de soja com inseticidas e um bioestimulante. Pesquisa Agropecuária Brasileira, v.43, p.13111318, 2008.

EMBRAPA. Manual de métodos de análise de solos. Brasília: Embrapa Produção de Informação; Rio de Janeiro: Embrapa Solos, 1997. 212p.

EMBRAPA. Sistema brasileiro de classificação de solos. Brasília: Embrapa Produção de Informaçáo; Rio de Janeiro: Embrapa Solos, 2006. 306p.

FAGERIA, N.K. Resposta de arroz de terras altas à correção de acidez em solo do cerrado. Pesquisa Agropecuária Brasileira, v.35, p.23032307, 2000.

FAGERIA, N.K.; BALIGAR, V.C. Ameliorating soil acidity of tropical Oxisols by liming for sustainable crop production. In: SPARKS, D.L. (Ed.). Advances in Agronomy. Amsterdan: Elsevier, 2008. p.345-399.

FAGERIA, N.K.; SANT'ANA, E.P; MORAES, O.P. Resposta de genótipos de arroz de sequeiro favorecido à fertilidade do solo. Pesquisa Agropecuária Brasileira, v.30, p.1155-1161, 1995.

FORNASIERI FILHO, D.; FORNASIERI, J.L. Manual da cultura do arroz. Jaboticabal: FUNEP, 1993. 221p.

GARCIA, R.A.; ROSOLEM, C.A. Agregados em um Latossolo sob sistema plantio direto e rotação de culturas. Pesquisa Agropecuária Brasileira, v.45, p.1489-1498, 2010.

GOURLEY, C.J.P.; ALLAN, D.L.; RUSSELE, M.P. Defining phosphorus efficiency in plants. Plant and Soil, v.155/156, p.289292, 1993.

GUIMARÁES, C.M.; STONE, L.F; NEVES, P.C.F. Resposta fenotípica de arroz de terras altas ao estresse de fósforo no solo. Revista Brasileira de Engenharia Agrícola e Ambiental, v.11, p.578-584, 2007.

HEINEMANN, A.B.; STONE, L.F.; FAGERIA, N.K. Transpiration rate response to water deficit during vegetative and reproductive phases of upland rice cultivars. Scientia Agricola, v.68, p.24-30, 2011.

HENRY, A.; GOWDA, V.R.P.; TORRES, R.O.; MCNALLY, K.L.; SERRAJ, R. Variation in root system architecture and drought response in Rice (Oryza sativa): phenotyping of the OryzaSNP panel in rainfed lowland fields. Field Crops Research, v.120, p.205-214, 2011.

LYNCH, J.P.; BROWN, K.M. Topsoil foraging - an architectural adaptation of plants to low phosphorus availability. Plant and Soil, v.237, p.225-237, 2001
MALAVOLTA, E.; VITTI, G.C.; OLIVEIRA, S.A. Avaliação do estado nutricional das plantas: princípios e aplicaçóes. Piracicaba: POTAFOS, 1997.319p.

MATSUO, N.; MOCHIZUKI, T. Growth and yield of six rice cultivars under three water-saving cultivations. Plant Production Science, v.12, p.514-525, 2009.

MAUAD, M.; CRUSCIOL, C.A.C.; ALVAREZ, R.C.F.; SILVA, R.H. Produção de matéria seca e absorção de nutrientes por cultivares de arroz de terras altas em resposta à calagem. Científica, v.32, p.178184,2004

MORAIS, O.P; CASTRO, E.M.; SOUZA, N.R.G.; PRABHU, A.S.; BASSINELLI, P.Z.; FONSECA, J.R. Cultivares de arroz de terras altas para o Mato Grosso. Santo Antônio de Goiás: Embrapa Arroz e Feijão, 2004. (Circular Técnica 68)

OLIVEIRA, F.H.T.; NOVAIS, R.F.; ALVAREZ, V.V.H.; CANTARUTTI, R.B.; BARROS, N.F. Fertilidade do solo no sistema Plantio Direto. In: ALVAREZ, V.V.H.; SCHAEFER, C.E.G.R.; BARROS, N.F.; MELLO, J.W.V.; COSTA, L.M. Tópicos em ciência do solo. Vol. II. Viçosa: Sociedade Brasileira de Ciência do Solo, 2002. p.393-486.

OTANI, T.; AE, N. Sensitivity of phosphorus uptake to change in root length and soil volume. Agronomy Journal, v.88, p.371-375, 1996.

PAVINATO, P.S.; AGUIAR, A.; CASTRO, G.S.A.; CRUSCIOL, C.A.C. Boro em arroz de terras altas cultivado em soluçáo nutritiva. Bragantia, v.68, p.743-751, 2009.

RAIJ, B. van; ANDRADE, J.C.; CANTARELLA, H.; QUAGGIO, J.A. Análise química para avaliação da fertilidade de solos tropicais. Campinas: Instituto Agronômico, 2001. 284p.

RAIJ, B. van; CANTARELA, H.; QUAGGIO, J.A.; FURLANI, A.M.C. Recomendaçóes de adubação e calagem para o Estado de São Paulo. 2 ed. Campinas: Instituto Agronômico, 1997. 285p.

ROSOLEM, C.A.; WERLE, R.; GARCIA, R.A. Nitrogen washing from $\mathrm{C}_{3}$ and $\mathrm{C}_{4}$ cover grasses residues by rain. Revista Brasileira de Ciência do Solo, v.34, p.1899-1905, 2010.

ROY, B.; MANDAL, A.B. Towards development of Al-toxicity tolerant lines in indica rice by exploiting somaclonal variation. Euphytica, v.145, p.221-227, 2005.

SORATTO, R.P.; CRUSCIOL, C.A.C. Dolomite and phosphogypsum surface application effects on annual crops nutrition and yield. Agronomy Journal, v.100, p.261-270, 2008.

SORATTO, R.P.; CRUSCIOL, C.A.C.; MELLO, F.F.C. Componentes da produção e produtividade de cultivares de arroz e feijão em funçáo de calcário e gesso aplicados na superfície do solo. Bragantia, v.69, p.965-974, 2010.

SWIADER, J.M.; CHYAN, Y.; FREIJI, G.G. Genotipic differences in nitrate uptake and utilization efficiency in pumpkin hybrids. Plant Nutrition, v.17, p.1687-1699, 1994.

WISSUWA, M. Combining a modeling with a genetic approach in establishing associations between genetic and physiological effects in relation to phosphorus uptake. Plant and Soil, v.269, p.57-68, 2005. 